\title{
Comparação de análises fitossociológicas e multivariadas na determinação do grau de conservação de áreas nativas de Cerrado
}

\author{
Comparison of phytosociological and multivariate analysis in the determination \\ of the conservation degree from native Cerrado areas
}

\author{
Jovan Martins Rios ${ }^{\mathrm{I}}$, Gabriel Venâncio Pereira Mariano ${ }^{\mathrm{II}}$, \\ Vanuza Pereira Garcia da Silva ${ }^{\mathrm{II}}$, Lilian Cristina da Silva Santos ${ }^{\mathrm{II}}$, \\ João Paulo Costa ${ }^{\mathrm{IV}}$, Lucas Ribeiro da Silva Zica ${ }^{\mathrm{v}}$, \\ Bianca Garcia dos Santos ${ }^{\mathrm{II}}$, Ana Flávia Costa Santos ${ }^{\mathrm{VI}}$, \\ Jamir Afonso do Prado Júnior ${ }^{\mathrm{VII}}$, Vagner Santiago do Vale
}

\section{Resumo}

\begin{abstract}
A forte pressão antrópica no Cerrado torna necessários estudos para averiguar o nível de conservação de áreas que estão sujeitas a essa atividade. Com isso, objetivo do trabalho foi comparar e avaliar a florística, a estrutura e o grau de conservação de duas áreas adjacentes de Cerrado, sendo uma área de cerrado conservado (CC) e outra de cerrado antropizado (CA). Foram utilizados os parâmetros fitossociológicos convencionais: densidade relativa (DR), dominância relativa (DoR), frequência relativa (FR) e o valor de importância (VI), além dos índices de diversidade de Shannon-Wiener e equitabilidade de Pielou. Foram feitas análises de ordenação pelo método DCA, dendrograma de classificação (UPGMA) a partir dos índices de Sørensen-Dice e Bray-Curtis, além da divisão hierárquica dicotômica por Twinspan. O teste t de Student foi utilizado para comparar as variáveis, classes diamétricas e classes de altura. O cerrado conservado apresentou valores maiores para número de indivíduos, classes diamétricas, área basal e altura. O índice de diversidade por parcelas, número de espécies, indivíduos e área basal total foram diferentes estatisticamente em relação as duas áreas. Através das análises multivariadas foi possível segregar as parcelas com base no grau de conservação, tanto na análise de ordenação (DCA) quanto de classificação (Dendrograma). Os métodos utilizados foram eficientes para demonstrar as diferenças entre as duas áreas, porém a análise multivariada se mostrou eficiente em fornecer maior detalhamento na diferenciação.
\end{abstract}

Palavras-chave: Diversidade; Antropização; Comunidades vegetais; Similaridade

Engenheiro Florestal, Doutorando, Escola de Agronomia, PPGA / Universidade Federal de Goiás, Campus Samambaia, Av. Esperança, s/n Chácaras de Recreio Samambaia, CEP 74690-900, Goiânia (GO), Brasil. jovan_jmr@hotmail.com (ORCID: 0000-0002-7635-6623)

II Estudante de Engenharia Florestal, Universidade Estadual de Goiás, Campus Ipameri, Vila Dona Nilza - Setor Universitário, CEP 75780-000, Ipameri (GO), Brasil. gabrielvenancio_@outlook.com (ORCID: 0000-0002-2418-951X) / garciavp@outlook.com (ORCID: 0000-0001-8003-681X)/ bigarcia78@gmail.com (ORCID: 0000-0002-4275-5853)

III Bióloga, Me., Universidade Estadual de Goiás, Campus Ipameri, Vila Dona Nilza - Setor Universitário, CEP 75780-000, Ipameri (GO), Brasil. liliancristina_@hotmail.com (ORCID: 0000-0002-6827-2438)

IV Biólogo, Doutorando, Universidade Federal de Uberlândia, Av. João Naves de Ávila, 2121 - Santa Mônica, CEP 38408-100, Uberlândia (MG), Brasil. joaopaulo_mc@hotmail.com (ORCID: 0000-0001-5271-8231)

Estudante de Agronomia, Universidade Estadual de Goiás, Campus Ipameri, Vila Dona Nilza - Setor Universitário, CEP 75780-000, Ipameri (GO), Brasil. lucasrzica@hotmail.com (ORCID: 0000-0002-8181-7746)

vi Engenheira Florestal, Mestranda. Universidade Estadual do Sudoeste da Bahia, Estrada do Bem Querer, Km 4, S/N, Campus de Candeias, CEP 45083-900, Vitória da Conquista (BA), Brasil. csanaflavia@hotmail.com (ORCID: 0000-0002-1010-348X)

VII Biólogo, Dr., Professor, Instituto de Biologia, Universidade Federal de Uberlândia, Av. Amazonas, 20 - Umuarama, CEP 38405-302, Uberlândia (MG), Brasil. jamirjunior@yahoo.com.br (ORCID: 0000-0003-1917-1283)

vIII Biólogo, Dr., Professor, Universidade Estadual de Goiás, Campus Ipameri, Vila Dona Nilza - Setor Universitário, CEP 75780-000, Ipameri (GO), Brasil.vsvale@hotmail.com (ORCID: 0000-0003-2155-9156) 


\begin{abstract}
The strong anthropic pressure in the Cerrado makes studies necessary to ascertain the level of conservation of areas that are subject to this activity. Thus, the objective of the work was to compare and evaluate the floristics, the structure and the degree of conservation of two adjacent areas of Cerrado, one area of conserved savanna (CC) and another of anthropized savanna (CA). Conventional phytosociological parameters were used: relative density (DR), relative dominance (DoR), relative frequency $(F R)$ and the importance value (VI), in addition to the Shannon-Wiener diversity index and Pielou's equitability. Sorting analyzes were performed using the DCA method, classification dendrogram (UPGMA) based on the Sørensen-Dice and Bray-Curtis indices, in addition to the dichotomous hierarchical division by Twinspan. Student's t-test was used to compare variables, diametric classes and height classes. The conserved savannah presented higher values for the number of individuals, diametric classes, basal area and height. The diversity index by plots, number of species, individuals and total basal area were statistically different for the two areas. Through multivariate analyzes it was possible to segregate the plots based on the degree of conservation, both in the ordering analysis (DCA) and in the classification (Dendrogram). The methods used were efficient to demonstrate the differences between the two areas, however the multivariate analysis proved to be efficient in providing greater detail in the differentiation.
\end{abstract}

Keywords: Diversity; Anthropic impacts; Arboreal community; Similarity

\title{
Introdução
}

O Cerrado em seu sentido amplo ocupa grande parte da porção central do Brasil, totalizando cerca de 200 milhões de hectares de área original, o que o torna o segundo maior domínio florístico do país (IBGE, 2004). O cerrado sentido restrito é a fisionomia mais típica desse bioma, sendo classificada como uma savana tropical, com semelhanças a outros presentes na América do Sul, África e Austrália, diferindo dessas principalmente por sua riqueza florística (LEHMAN et al., 2014). A pesar da rica biodiversidade de sua flora e fauna, nota-se a forte dinâmica de ocupação humana em suas áreas (SANO et al., 2007), incluindo tanto o desmatamento quanto os incêndios florestais, o que ocasiona alteração da paisagem, fragmentação de habitat, e até mesmo extinção de espécies. Devido à constância de queimadas, muitas espécies apresentam alto grau de resiliência pós-fogo (MIRANDA et al., 2004) o que favorece uma determinada composição florística em que ocorrem eventos de fogo frequentes (FELFILI et al., 2000). Contudo, embora a vegetação lenhosa do Cerrado apresente características adaptativas ao fogo, as queimadas nem sempre são frequentes em determinadas áreas, o que pode culminar em modificações estruturais na comunidade (PINHEIRO; DURIGAN, 2009). Sem a presença constante de incêndios, esperase que outras espécies, sem a necessidade de gastos energéticos e estruturais para a sobrevivência sob queimadas, devam ocupar áreas protegidas do fogo.

O Cerrado tornou-se então o segundo ecossistema brasileiro que mais sofreu com a ocupação humana (SLOAN et al., 2014). Esse fato levou ao risco de extinção de inúmeras espécies e, mesmo com o reconhecimento da importância biológica, o Cerrado é o que possui a menor porcentagem de áreas sobre proteção integral, apresentando apenas $8,21 \%$ de seu território legalmente protegido por unidades de conservação (BRASIL, 2016). As atividades humanas mais significativas no Bioma têm ocorrido devido à gradativa conversão da vegetação nativa por atividades agropecuárias que já levaram à perda de parte da área original do Cerrado, reduzida em mais de 73,8\% (FELFILI et al., 2000). No entanto, é negligenciado o papel dessa matriz agrária na possível elevação nutricional, sendo que grande parte dos cerrados estão dentro de reservas legais, ou no mínimo, muito próximas a culturas nas quais se utilizam diversos insumos agrícolas. Assim, é impossível negar que sob as atuais condições, os cerrados deverão sempre estar em uma matriz agropecuária e esta deve influenciar os cerrados ao longo do tempo.

Para a preservação de áreas de cerrado que lidam com a atual pressão antrópica, são requeridos estudos para a aferição do grau de conservação da área, e para tal são realizados estudos florísticos, fitossociológicos e da ecologia das espécies componentes (GUSSOM et al., 
2012). Porém, considerando-se os estudos já feitos, existe escassez da utilização de técnicas de análises multivariadas. A denominação "Análise Multivariada” corresponde a um grande número de métodos e técnicas que utilizam, simultaneamente, todas as variáveis na interpretação teórica do conjunto de dados obtidos (GOTELLI; CHAO, 2013). Com o interesse de verificar como as amostras se relacionam, tais análises permitem uma comparação detalhada a fim de fornecerem novas informações capazes de aferir o estádio de conservação de cerrados nativos.

No campus Ipameri, da Universidade Estadual de Goiás, existe uma área de cerrado aparentemente em boas condições com ocorrência de queimadas nos últimos anos, entretanto sem histórico de uso para pastagem. Há outra área localizada nas proximidades, que foi utilizada para pastagens durante pelo menos 50 anos, mas que cessaram no início dos anos 2000 e possui o mesmo histórico de queima recente.

Considerando que diferentes históricos de perturbação e estado de conservação tornam cada remanescente único na sua riqueza e estrutura, o objetivo deste trabalho foi comparar e avaliar essas duas áreas por meio de análises que envolvam a estrutura e a flora de ambas por meio de técnicas de análises fitossociológicas comumente utilizada em relatórios técnicos e artigos científicos e por meio de análises multivariadas de dados, para comparar a eficiência de ambos em determinar o grau de conservação de cada área.

\section{Material e método}

\section{Caracterização da área de estudo}

O estudo foi realizado de janeiro a setembro de 2016, no campus da Universidade Estadual

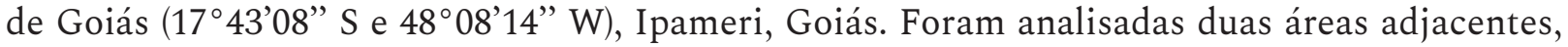
uma de cerrado conservado (CC) e outra de cerrado antropizado (CA).

O campus possui uma área aproximada de $243 \mathrm{ha}^{-1}$, cuja ocupação principal é o cultivo comercial, salvo fragmentos de cerrado stricto sensu, cerradão e de mata de galeria. As condições climáticas da região são do tipo Aw (KOTTEK et al., 2006) com dois períodos climáticos bem definidos: um seco e frio (de abril a setembro) com média pluviométrica de $214 \mathrm{~mm}$ e outro quente e chuvoso (de outubro a março) com $1317 \mathrm{~mm}$, a temperatura média anual é de $21,6^{\circ} \mathrm{C}$ com mínima de $20,2^{\circ} \mathrm{C}$ no inverno e $22,9^{\circ} \mathrm{C}$ nos meses de verão (ALVARES et al., 2014). O solo predominante da região é Latossolo Vermelho Distroférrico (EMBRAPA, 2006).

\section{Coleta de dados}

Para a realização do levantamento fitossociológico nas duas áreas, adotou-se o método de parcelas. Foram implantadas 10 parcelas no CC e 10 parcelas no CA de 20 x 50 m, totalizando um hectare em cada área. Estabeleceu-se a distância mínima de $50 \mathrm{~m}$ entre as parcelas para garantir a independência das unidades amostrais. Foram amostrados todos os indivíduos arbóreos que atingiram circunferência igual ou superior a $15 \mathrm{~cm}$ a $0,3 \mathrm{~m}$ à altura do solo, metodologia proposta pela Rede de Parcelas Permanentes dos Biomas Cerrado e Pantanal (FELFILI; CARVALHO; HAIDAR, 2005). Registrou-se a altura total utilizando um podão de coleta de $9 \mathrm{~m}$ graduada metro a metro como referência. Foram considerados como mortos aqueles indivíduos cujo tronco principal não possuía tecidos vivos ou folhas, mesmo no auge da estação chuvosa. As identificações taxonômicas foram feitas no laboratório da Universidade Estadual de Goiás, sendo também realizadas consultas às bibliografias especializadas.

Os parâmetros fitossociológicos de densidade relativa (DR), dominância relativa (DoR) e frequência relativa (FR) e o valor de importância (VI) seguiram Eisenlohr et al. (2011). Para a estimativa do índice de diversidade de Shannon-Weaver (H') e equabilidade de Pielou (J') foi usado o software PAST 2.17c (HAMMER et al., 2001). 
Foi utilizado teste t de Student (GOTELLI; ELISSON, 2011) a fim de comparar as espécies, o número de indivíduos, área basal total, índice de diversidade de Shannon-Wiener e índice de equitabilidade de Pielou por parcela entre as duas áreas (CC e CA).

A riqueza de espécies entre o CC e CA foi comparada por meio do método de rarefação baseado na área amostral (GOTELLI; CHAO, 2013), usando o estimador Sobs (Mao Tau) com 1000 randomizações. A riqueza florística das duas áreas foi estimada pelo método de Bootstrap, escolhido por apresentar uma alta correlação entre os valores estimados e observados (WANG, 2011). As análises de rarefação foram realizadas no software EstimateS 9.1.0 (purl.oclc.org/ estimates) (Robert K. Colwell, University of Connecticut, USA, 2013).

Foram realizadas classes de diâmetro e altura definidas pela fórmula:

$$
\frac{A}{K}
$$

Em que: $\mathrm{A}$ = representa a amplitude para o parâmetro (diâmetro ou altura); $\mathrm{K}$ = é definido pelo algoritmo de Sturges: $\mathrm{K}=1+3,3 \mathrm{x} \log \mathrm{N}$, sendo $\mathrm{N}$ o número de indivíduos amostrados (EISENLOHR et al., 2011).

\section{Análise de Dados}

\section{Similaridade e Análises multivariadas}

Para avaliar a similaridade florística entre o CC e o CA foi utilizado o índice qualitativo de Sørensen-Dice a partir de uma matriz de presença/ausência de espécies e o índice quantitativo de Bray-Curtis (GOTELLI; CHAO, 2013) para o número de indivíduos por espécie nas parcelas das duas áreas. Os valores calculados para similaridade foram utilizados para produzir o dendrograma de classificação, utilizando a média de ligação de grupo (UPGMA) como método de agrupamento.

A partir dos dados florísticos quantitativos das espécies arbóreas foi feita a ordenação dos dados através da análise de correspondência retificada (DCA - Detrended Correspondence Analysis). Para definir as espécies indicadoras dos grupos florísticos, utilizou-se também a divisão hierárquica dicotômica por Twinspan (two-way indicator species analysis) (HILL, 1979), a partir da matriz composta pelas 82 espécies e sua distribuição nas duas áreas. As análises foram efetuadas através do software FITOPAC 2.1.2.85 (SHEPHERD, 2010).

\section{Resultados e discussão}

Abordagem fitossociológica (Fitossociologia, curva do coletor e classes de tamanho)

Em conjunto, nas duas áreas de cerrado foram amostras 80 espécies, 63 gêneros e 35 famílias. Foram registradas 67 espécies, 58 gêneros e 34 famílias no cerrado conservado (CC) e 40 espécies, 30 gêneros e 18 famílias no cerrado antropizado (CA). Ao todo, 25 espécies foram encontradas em ambas as áreas, 41 foram exclusivas do CC e 14 do CA (Tabela 1). No total foram registrados 10 indivíduos mortos em pé no CC $(1,48 \%)$ e 5 no CA $(2,6 \%)$.

Dentre as dez espécies com maior VI no CC (70,26\% dos indivíduos e 72,93\% da área basal) e no CA (64,06\% dos indivíduos e $72,54 \%$ da área basal), apenas três são comuns nas duas áreas, porém com diferentes posições fitossociológicas: Qualea grandiflora; Terminalia argentea; Annona crassiflora. As três famílias de maior destaque para CC e CA com relação ao número de indivíduos foram respectivamente Vochysiaceae (32,99\%), Fabaceae $(15,38 \%)$ e Annonaceae $(13,17 \%)$; e Vochysiaceae (31,25\%), Fabaceae (25\%), Annonaceae (8,85\%). 
Tabela 1 - Parâmetros fitossociológicos das espécies amostradas em um cerrado conservado (CC) e cerrado antropizado (CA), em ordem decrescente de VI\% das espécies do CC, do campus da Universidade Estadual de Goiás, Ipameri - GO

Table 1 - Phytosociological parameters of the species sampled in a conserved cerrado (CC) and anthropic cerrado (CA), in decreasing order of VI\% of species of CC, of the Goiás State University Campus, Ipameri - GO

\begin{tabular}{|c|c|c|c|c|c|c|c|c|c|c|c|}
\hline \multirow{2}{*}{ Espécies } & \multirow{2}{*}{ Família } & \multicolumn{2}{|c|}{ N.ind } & \multicolumn{2}{|c|}{ DeR } & \multicolumn{2}{|c|}{ FR } & \multicolumn{2}{|c|}{ DoR } & \multicolumn{2}{|c|}{ VI\% } \\
\hline & & $\mathrm{CC}$ & CA & $\mathrm{CC}$ & CA & $\mathrm{CC}$ & CA & $\mathrm{CC}$ & CA & $\mathrm{CC}$ & CA \\
\hline $\begin{array}{l}\text { Qualea grandiflora } \\
\text { Mart. }\end{array}$ & Vochysiaceae & 175 & 57 & 25,89 & 29,69 & 4,93 & 9,38 & 24,94 & 39,30 & 18,59 & 26,12 \\
\hline $\begin{array}{l}\text { Xylopia aromatica } \\
\text { (Lam.) Mart. }\end{array}$ & Annonaceae & 75 & 10 & 11,09 & 5,21 & 4,93 & 1,04 & 5,22 & 1,35 & 7,08 & 2,53 \\
\hline $\begin{array}{l}\text { Caryocar brasiliense } \\
\text { Cambess. }\end{array}$ & Caryocaraceae & 35 & 4 & 5,18 & 2,08 & 4,43 & 2,08 & 10,06 & 2,25 & 6,56 & 2,14 \\
\hline $\begin{array}{l}\text { Qualea parviflora } \\
\text { Mart. }\end{array}$ & Vochysiaceae & 40 & 3 & 5,92 & 1,56 & 4,43 & 3,13 & 7,73 & 2,32 & 6,03 & 2,34 \\
\hline $\begin{array}{l}\text { Tachigali paniculata } \\
\text { Aubl. }\end{array}$ & Fabaceae & 37 & 0 & 5,47 & - & 4,43 & - & 4,62 & - & 4,84 & - \\
\hline $\begin{array}{l}\text { Terminalia argentea } \\
\text { Mart. \& Zucc }\end{array}$ & Combretaceae & 31 & 6 & 4,59 & 3,13 & 4,93 & 1,04 & 4,69 & 6,31 & 4,73 & 3,49 \\
\hline $\begin{array}{l}\text { Tapirira guianensis } \\
\text { Aubl. }\end{array}$ & Anacardiaceae & 22 & 0 & 3,25 & - & 2,46 & - & 7,27 & - & 4,33 & - \\
\hline Tachigali aurea Tul. & Fabaceae & 25 & 1 & 3,70 & 0,52 & 3,94 & 1,04 & 4,78 & 1,41 & 4,14 & 0,99 \\
\hline $\begin{array}{l}\text { Annona crassiflora } \\
\text { Mart. }\end{array}$ & Annonaceae & 14 & 5 & 2,07 & 2,60 & 3,94 & 4,17 & 2,13 & 2,19 & 2,71 & 2,99 \\
\hline $\begin{array}{l}\text { Roupala montana } \\
\text { Aubl. }\end{array}$ & Proteaceae & 21 & 1 & 3,11 & 0,52 & 3,45 & 1,04 & 1,49 & 0,25 & 2,68 & 0,60 \\
\hline $\begin{array}{l}\text { Emmotum nitens } \\
\text { (Benth.) Miers. }\end{array}$ & Metteniusaceae & 12 & 0 & 1,78 & - & 1,97 & - & 2,72 & - & 2,15 & - \\
\hline $\begin{array}{l}\text { Myrcia splendens } \\
\text { (Sw.) DC }\end{array}$ & Myrtaceae & 12 & 0 & 1,78 & - & 1,97 & - & 2,42 & - & 2,06 & - \\
\hline $\begin{array}{l}\text { Plenckia populnea } \\
\text { Reissek }\end{array}$ & Celastraceae & 11 & 0 & 1,63 & - & 2,96 & - & 1,37 & - & 1,98 & - \\
\hline Mortas em pé & - & 10 & 5 & 1,48 & 2,60 & 2,46 & 5,21 & 1,79 & 2,09 & 1,91 & 3,30 \\
\hline $\begin{array}{l}\text { Lafoensia pacari A. } \\
\text { St.-Hil. }\end{array}$ & Lythraceae & 10 & 0 & 1,48 & - & 2,46 & - & 1,21 & - & 1,72 & - \\
\hline $\begin{array}{l}\text { Matayba guianensis } \\
\text { Aubl. }\end{array}$ & Sapindaceae & 9 & 1 & 1,33 & 0,52 & 1,97 & 1,04 & 1,09 & 0,42 & 1,47 & 0,66 \\
\hline $\begin{array}{l}\text { Siparuna guianensis } \\
\text { Aubl. }\end{array}$ & Siparunaceae & 10 & 0 & 1,48 & - & 1,97 & - & 0,82 & - & 1,42 & - \\
\hline $\begin{array}{l}\text { Bowdichia } \\
\text { virgilioides Kunth }\end{array}$ & Fabaceae & 5 & 1 & 0,74 & 0,52 & 1,97 & 1,04 & 1,30 & 0,16 & 1,34 & 0,57 \\
\hline
\end{tabular}


Tabela 1 - Continuação ...

Table 1 - Continuation ...

\begin{tabular}{|c|c|c|c|c|c|c|c|c|c|c|c|}
\hline \multirow{2}{*}{ Espécies } & \multirow{2}{*}{ Família } & \multicolumn{2}{|c|}{ N.ind } & \multicolumn{2}{|c|}{ DeR } & \multicolumn{2}{|c|}{ FR } & \multicolumn{2}{|c|}{ DoR } & \multicolumn{2}{|c|}{ VI\% } \\
\hline & & $\mathrm{CC}$ & CA & $\mathrm{CC}$ & $\mathrm{CA}$ & $\mathrm{CC}$ & CA & $\mathrm{CC}$ & CA & $\mathrm{CC}$ & CA \\
\hline $\begin{array}{l}\text { Dimorphandra } \\
\text { mollis Benth. }\end{array}$ & Fabaceae & 7 & 11 & 1,04 & 5,73 & 1,97 & 6,25 & 0,54 & 4,60 & 1,18 & 5,53 \\
\hline $\begin{array}{l}\text { Diospyros lasiocalyx } \\
\text { (Mart.) B. Walln. }\end{array}$ & Ebenaceae & 5 & 7 & 0,74 & 3,65 & 1,48 & 2,08 & 1,00 & 3,69 & 1,07 & 3,14 \\
\hline Tachigali sp. & Fabaceae & 7 & 0 & 1,04 & - & 0,99 & - & 1,10 & - & 1,04 & - \\
\hline $\begin{array}{l}\text { Vochysia tucanorum } \\
\text { Mart. }\end{array}$ & Vochysiaceae & 6 & 0 & 0,89 & - & 0,99 & - & 1,07 & - & 0,98 & - \\
\hline $\begin{array}{l}\text { Astronium } \\
\text { fraxinifolium Schott }\end{array}$ & Anacardiaceae & 4 & 2 & 0,59 & 1,04 & 1,97 & 2,08 & 0,31 & 0,24 & 0,96 & 1,12 \\
\hline $\begin{array}{l}\text { Byrsonima } \\
\text { verbascifolia }(\mathbf{L} .) \\
\text { DC. }\end{array}$ & Malpighiaceae & 5 & 1 & 0,74 & 0,52 & 1,48 & 1,04 & 0,63 & 0,76 & 0,95 & 0,77 \\
\hline $\begin{array}{l}\text { Plathymenia } \\
\text { reticulata Benth. }\end{array}$ & Fabaceae & 4 & 0 & 0,59 & - & 1,48 & - & 0,23 & - & 0,77 & - \\
\hline $\begin{array}{l}\text { Byrsonima } \\
\text { coccolobifolia Kunth }\end{array}$ & Malpighiaceae & 3 & 3 & 0,44 & 1,56 & 1,48 & 3,13 & 0,28 & 1,79 & 0,73 & 2,16 \\
\hline $\begin{array}{l}\text { Stryphnodendron } \\
\text { adstringens (Mart.) } \\
\text { Coville. }\end{array}$ & Fabaceae & 5 & 11 & 0,74 & 5,73 & 0,99 & 6,25 & 0,45 & 5,58 & 0,73 & 5,85 \\
\hline $\begin{array}{l}\text { Leptolobium elegans } \\
\text { Vogel }\end{array}$ & Fabaceae & 4 & 1 & 0,59 & 0,52 & 0,99 & 1,04 & 0,57 & 0,28 & 0,71 & 0,61 \\
\hline $\begin{array}{l}\text { Brosimum } \\
\text { gaudichaudii Trécul }\end{array}$ & Moraceae & 4 & 0 & 0,59 & - & 0,99 & - & 0,28 & - & 0,62 & - \\
\hline $\begin{array}{l}\text { Protium } \\
\text { heptaphyllum } \\
\text { (Aubl.) Marchand }\end{array}$ & Burseraceae & 4 & 0 & 0,59 & - & 0,49 & - & 0,69 & - & 0,59 & - \\
\hline $\begin{array}{l}\text { Tabebuia aurea } \\
\text { (Silva Manso) } \\
\text { Benth. \&Hook f. ex } \\
\text { S. More }\end{array}$ & Bignoniaceae & 3 & 0 & 0,44 & - & 0,99 & - & 0,32 & - & 0,58 & - \\
\hline $\begin{array}{l}\text { Pterodon } \\
\text { emarginatus Vogel }\end{array}$ & Fabaceae & 3 & 0 & 0,44 & - & 0,99 & - & 0,21 & - & 0,55 & - \\
\hline $\begin{array}{l}\text { Cordiera humilis (K. } \\
\text { Schum.) Kuntze }\end{array}$ & Rubiaceae & 3 & 0 & 0,44 & - & 0,99 & - & 0,20 & - & 0,54 & - \\
\hline Virola sebifera Aubl. & Myristicaceae & 3 & 0 & 0,44 & - & 0,99 & - & 0,19 & - & 0,54 & - \\
\hline $\begin{array}{l}\text { Himatanthus } \\
\text { obovatus (Müll. } \\
\text { Arg.) Woodson. }\end{array}$ & Apocynaceae & 2 & 0 & 0,30 & - & 0,99 & - & 0,29 & - & 0,52 & - \\
\hline $\begin{array}{l}\text { Byrsonima } \\
\text { pachyphylla A. Juss. }\end{array}$ & Malpighiaceae & 3 & 1 & 0,44 & 0,52 & 0,99 & 1,04 & 0,11 & 0,09 & 0,51 & 0,55 \\
\hline
\end{tabular}


Tabela 1 - Continuação ...

Table 1 - Continuation ...

\begin{tabular}{|c|c|c|c|c|c|c|c|c|c|c|c|}
\hline \multirow{2}{*}{ Espécies } & \multirow{2}{*}{ Família } & \multicolumn{2}{|c|}{ N.ind } & \multicolumn{2}{|c|}{ DeR } & \multicolumn{2}{|c|}{ FR } & \multicolumn{2}{|c|}{ DoR } & \multicolumn{2}{|c|}{ VI\% } \\
\hline & & $\mathrm{CC}$ & CA & $\mathrm{CC}$ & CA & $\mathrm{CC}$ & CA & $\mathrm{CC}$ & $\mathrm{CA}$ & $\mathrm{CC}$ & CA \\
\hline $\begin{array}{l}\text { Diospyros hispida } \\
\text { A. DC. }\end{array}$ & Ebenaceae & 2 & 5 & 0,30 & 2,60 & 0,99 & 4,17 & 0,26 & 1,75 & 0,51 & 2,84 \\
\hline $\begin{array}{l}\text { Vatairea macrocarpa } \\
\text { (Benth.) Ducke }\end{array}$ & Fabaceae & 2 & 0 & 0,30 & - & 0,99 & - & 0,25 & - & 0,51 & - \\
\hline $\begin{array}{l}\text { Eriotheca pubescens } \\
\text { (Mart. \& Zucc.) } \\
\text { Schott \& Endl. }\end{array}$ & Malvaceae & 1 & 0 & 0,15 & - & 0,49 & - & 0,87 & - & 0,51 & - \\
\hline $\begin{array}{l}\text { Richeria grandis } \\
\text { Vahl }\end{array}$ & Phyllanthaceae & 1 & 0 & 0,15 & - & 0,49 & - & 0,81 & - & 0,48 & - \\
\hline $\begin{array}{l}\text { Hirtella glandulosa } \\
\text { Spreng. }\end{array}$ & Chrysobalanaceae & 2 & 0 & 0,30 & - & 0,99 & - & 0,16 & - & 0,48 & - \\
\hline $\begin{array}{l}\text { Licania apetala (E. } \\
\text { Mey.) Fritsch }\end{array}$ & Chrysobalanaceae & 2 & 0 & 0,30 & - & 0,99 & - & 0,14 & - & 0,48 & - \\
\hline $\begin{array}{l}\text { Kielmeyera coriácea } \\
\text { Mart. \& Zucc. }\end{array}$ & Calophyllaceae & 2 & 1 & 0,30 & 0,52 & 0,99 & 1,04 & 0,10 & 0,55 & 0,46 & 0,70 \\
\hline $\begin{array}{l}\text { Piptocarpha } \\
\text { rotundifolia (Less.) } \\
\text { Baker }\end{array}$ & Asteraceae & 2 & 5 & 0,30 & 2,60 & 0,99 & 3,13 & 0,10 & 1,45 & 0,46 & 2,39 \\
\hline $\begin{array}{l}\text { Erythroxylum } \\
\text { deciduum A. St.-Hil. }\end{array}$ & Erythroxylaceae & 2 & 2 & 0,30 & 1,04 & 0,99 & 2,08 & 0,07 & 0,86 & 0,45 & 1,33 \\
\hline $\begin{array}{l}\text { Eremanthus } \\
\text { glomerulatus Less. }\end{array}$ & Asteraceae & 4 & 0 & 0,59 & - & 0,49 & - & 0,22 & - & 0,44 & - \\
\hline $\begin{array}{l}\text { Alibertia edulis } \\
\text { (Rich.) A. Rich. }\end{array}$ & Rubiaceae & 4 & 0 & 0,59 & - & 0,49 & - & 0,20 & - & 0,43 & - \\
\hline $\begin{array}{l}\text { Styrax camporum } \\
\text { Pohl }\end{array}$ & Styracaceae & 1 & 0 & 0,15 & - & 0,49 & - & 0,50 & - & 0,38 & - \\
\hline $\begin{array}{l}\text { Vochysia thyrsoidea } \\
\text { Pohl }\end{array}$ & Vochysiaceae & 2 & 0 & 0,30 & - & 0,49 & - & 0,29 & - & 0,36 & - \\
\hline $\begin{array}{l}\text { Strychnos } \\
\text { pseudoquina A. } \\
\text { St.-Hil. }\end{array}$ & Loganiaceae & 2 & 0 & 0,30 & - & 0,49 & - & 0,12 & - & 0,30 & - \\
\hline $\begin{array}{l}\text { Connarus suberosus } \\
\text { Planch. }\end{array}$ & Connaraceae & 1 & 0 & 0,15 & - & 0,49 & - & 0,27 & - & 0,30 & - \\
\hline $\begin{array}{l}\text { Eriotheca } \\
\text { candolleana (K. } \\
\text { Schum.) A. Robyns }\end{array}$ & Malvaceae & 1 & 0 & 0,15 & - & 0,49 & - & 0,23 & - & 0,29 & - \\
\hline $\begin{array}{l}\text { Cecropia } \\
\text { pachystachya Trécul }\end{array}$ & Urticaceae & 1 & 0 & 0,15 & - & 0,49 & - & 0,22 & - & 0,29 & - \\
\hline $\begin{array}{l}\text { Monteverdia } \\
\text { floribunda (Reissek) } \\
\text { Biral }\end{array}$ & Celastraceae & 1 & 0 & 0,15 & - & 0,49 & - & 0,17 & - & 0,27 & - \\
\hline
\end{tabular}


Tabela 1 - Continuação ...

Table 1 - Continuation ...

\begin{tabular}{|c|c|c|c|c|c|c|c|c|c|c|c|}
\hline \multirow{2}{*}{ Espécies } & \multirow{2}{*}{ Família } & \multicolumn{2}{|c|}{ N.ind } & \multicolumn{2}{|c|}{ DeR } & \multicolumn{2}{|c|}{ FR } & \multicolumn{2}{|c|}{ DoR } & \multicolumn{2}{|c|}{ VI\% } \\
\hline & & $\mathrm{CC}$ & CA & $\mathrm{CC}$ & CA & $\mathrm{CC}$ & CA & $\mathrm{CC}$ & CA & $\mathrm{CC}$ & CA \\
\hline $\begin{array}{l}\text { Hymenaea courbaril } \\
\text { L. }\end{array}$ & Fabaceae & 1 & 2 & 0,15 & 1,04 & 0,49 & 2,08 & 0,14 & 0,55 & 0,26 & 1,40 \\
\hline $\begin{array}{l}\text { Davilla elliptica A. } \\
\text { St.-Hil. }\end{array}$ & Dilleniaceae & 1 & 0 & 0,15 & - & 0,49 & - & 0,13 & - & 0,26 & - \\
\hline $\begin{array}{l}\text { Handroanthus } \\
\text { serratifolius (Vahl) } \\
\text { S. Grose }\end{array}$ & Bignoniaceae & 1 & 0 & 0,15 & - & 0,49 & - & 0,10 & - & 0,25 & - \\
\hline $\begin{array}{l}\text { Handrotanthus } \\
\text { ochraceus (Cham.) } \\
\text { Mattos }\end{array}$ & Bignoniaceae & 1 & 2 & 1,19 & - & 0,49 & 2,08 & 0,08 & 0,55 & 0,24 & 1,09 \\
\hline $\begin{array}{l}\text { Curatella americana } \\
\text { L. }\end{array}$ & Dilleniaceae & 1 & 6 & 0,15 & 3,13 & 0,49 & 4,17 & 0,08 & 2,47 & 0,24 & 3,26 \\
\hline $\begin{array}{l}\text { Aspidosperma } \\
\text { subincanun Mart. }\end{array}$ & Apocynaceae & 1 & 0 & 0,15 & - & 0,49 & - & 0,07 & - & 0,24 & - \\
\hline Rubiaceae sp. & Rubiaceae & 1 & 0 & 0,15 & - & 0,49 & - & 0,06 & - & 0,23 & - \\
\hline $\begin{array}{l}\text { Machaerium } \\
\text { opacum Vogel }\end{array}$ & Fabaceae & 1 & 8 & 0,15 & 4,17 & 0,49 & 5,21 & 0,05 & 2,38 & 0,23 & 3,92 \\
\hline $\begin{array}{l}\text { Rudgea viburnoides } \\
\text { (Cham.) Benth. }\end{array}$ & Rubiaceae & 1 & 0 & 0,15 & - & 0,49 & - & 0,05 & - & 0,23 & - \\
\hline Ilex affinis Gardner & Aquifoliaceae & 1 & 0 & 0,15 & - & 0,49 & - & 0,03 & - & 0,22 & - \\
\hline $\begin{array}{l}\text { Zanthoxylum } \\
\text { rhoifolium Lam. }\end{array}$ & Rutaceae & 1 & 0 & 0,15 & - & 0,49 & - & 0,03 & - & 0,22 & - \\
\hline $\begin{array}{l}\text { Enterolobium } \\
\text { gummiferum (Mart.) } \\
\text { J.F. Macbr. }\end{array}$ & Fabaceae & 1 & 0 & 0,15 & - & 0,49 & - & 0,03 & - & 0,22 & - \\
\hline $\begin{array}{l}\text { Senna silvestris } \\
\text { (Vell.) H. S. Irwin \& } \\
\text { Barneby. }\end{array}$ & Fabaceae & 1 & 0 & 0,15 & - & 0,49 & - & 0,03 & - & 0,22 & - \\
\hline $\begin{array}{l}\text { Dalbergia } \\
\text { miscolobium Benth. }\end{array}$ & Fabaceae & 1 & 1 & 0,15 & 0,52 & 0,49 & 1,04 & 0,02 & 0,14 & 0,22 & 0,57 \\
\hline $\begin{array}{l}\text { Tachigali vulgaris } \\
\text { L. G. Silva \& H. C. } \\
\text { Lima }\end{array}$ & Fabaceae & 0 & 7 & - & 3,65 & - & 5,21 & - & 3,91 & - & 4,25 \\
\hline $\begin{array}{l}\text { Astronium } \\
\text { graveolens Jacq. }\end{array}$ & Anacardiaceae & 0 & 3 & - & 1,56 & - & 1,04 & - & 2,67 & - & 1,76 \\
\hline $\begin{array}{l}\text { Pterodon pubescens } \\
\text { (Benth.) Benth. }\end{array}$ & Fabaceae & 0 & 1 & - & 0,52 & - & 1,04 & - & 3,59 & - & 1,72 \\
\hline $\begin{array}{l}\text { Couepia grandiflora } \\
\text { (Mart. \& Zucc.) } \\
\text { Benth. }\end{array}$ & Chrysobalanaceae & 0 & 4 & - & 2,08 & - & 2,08 & - & 0,67 & - & 1,61 \\
\hline
\end{tabular}


Tabela 1 - Conclusão ...

Table 1 - Conclusion ...

\begin{tabular}{|c|c|c|c|c|c|c|c|c|c|c|c|}
\hline \multirow{2}{*}{ Espécies } & \multirow{2}{*}{ Família } & \multicolumn{2}{|c|}{ N.ind } & \multicolumn{2}{|c|}{ DeR } & \multicolumn{2}{|c|}{ FR } & \multicolumn{2}{|c|}{ DoR } & \multicolumn{2}{|c|}{ VI\% } \\
\hline & & $\mathrm{CC}$ & CA & $\mathrm{CC}$ & CA & $\mathrm{CC}$ & $\mathrm{CA}$ & $\mathrm{CC}$ & $\mathrm{CA}$ & $\mathrm{CC}$ & CA \\
\hline $\begin{array}{l}\text { Erythroxylum } \\
\text { suberosum A. St.- } \\
\text { Hil. }\end{array}$ & Erythroxylaceae & 0 & 3 & - & 1,56 & - & 2,08 & - & 0,73 & - & 1,46 \\
\hline $\begin{array}{l}\text { Leptolobium } \\
\text { dasycarpum Vogel }\end{array}$ & Fabaceae & 0 & 4 & - & 2,08 & - & 3,12 & - & 0,36 & - & 1,88 \\
\hline $\begin{array}{l}\text { Annona coriácea } \\
\text { Mart. }\end{array}$ & Annonaceae & 0 & 2 & - & 1,04 & - & 2,08 & - & 0,37 & - & 1,16 \\
\hline $\begin{array}{l}\text { Zeyheria montana } \\
\text { Mart. }\end{array}$ & Bignoniaceae & 0 & 1 & - & 0,52 & - & 1,04 & - & 0,74 & - & 0,77 \\
\hline $\begin{array}{l}\text { Pouteria torta } \\
\text { (Mart.) Radlk. }\end{array}$ & Sapotaceae & 0 & 1 & - & 0,52 & - & 1,04 & - & 0,60 & - & 0,72 \\
\hline $\begin{array}{l}\text { Pouteria ramiflora } \\
\text { (Mart.) Radlk. }\end{array}$ & Sapotaceae & 0 & 1 & - & 0,52 & - & 1,04 & - & 0,22 & - & 0,59 \\
\hline $\begin{array}{l}\text { Handroanthus albus } \\
\text { (Cham.) Mattos }\end{array}$ & Bignoniaceae & 0 & 1 & - & 0,52 & - & 1,04 & - & 0,20 & - & 0,59 \\
\hline $\begin{array}{l}\text { Pseudobombax } \\
\text { longiflorum (Mart.) } \\
\text { A. Robyns }\end{array}$ & Malvaceae & 0 & 1 & - & 0,52 & - & 1,04 & - & 0,15 & - & 0,57 \\
\hline Total & & 676 & 192 & 100 & 100 & 100 & 100 & 100 & 100 & 100 & 100 \\
\hline
\end{tabular}

Fonte: Autores (2018)

Em que: $\mathrm{N}$.ind = Número de indivíduos, DeR = densidade relativa (\%), FR = frequência relativa (\%), DoR = dominância relativa $(\%)$ e VI\% = valor de importância em porcentagem.

O número estimado de riqueza de espécies $\left(\mathrm{S}_{\mathrm{obs}}-\mathrm{Mao}\right.$ Tau) para o CA, com esforço amostral de 192 indivíduos, foi de 42, variando de 35 a 50 (intervalo de confiança de 95\%), indicando menor riqueza florística no CA em relação ao CC. Nessa área, o esforço amostral foi de 676 indivíduos. O número estimado de riqueza foi de 73, variando de 65 a 81 (intervalo de confiança de $95 \%$ ). O número de espécies registrados para CC e CA representam $83,19 \%$ e 79,38\%, respectivamente, comparados aos valores estimados pelo método de Bootstrap $(n=86,06 \pm 2,3$ espécies para CC e $n=50,39 \pm 2,7$ espécies para CA). A curva de rarefação ( $\mathrm{S}_{\text {obs }}$ - Mao Tau) não estabilizou para ambas as áreas (Figura 1).

A densidade de indivíduos foi de 676 indivíduos.ha $^{-1}$ no CC e 192 indivíduos.ha $^{-1}$ no CA. A área basal total dos indivíduos vivos foi de $17,02 \mathrm{~m}^{2} \cdot \mathrm{ha}^{-1}$ no CC e $4,08 \mathrm{~m}^{2} \cdot \mathrm{ha}^{-1}$ no CA. A densidade de indivíduos, o número de espécies, área basal total e o índice de diversidade de espécies de ShannonWeaver $\left(H^{\prime}\right)$ por parcela foram diferentes estatisticamente $(\mathrm{p}<0,05)$ entre o CC comparado a CA. No entanto, o índice de equitabilidade de Pielou (J') por parcela foi semelhante entre as áreas (Tabela 2).

As duas áreas estudadas apresentaram um número maior de indivíduos com diâmetros menores concentrados nas duas primeiras classes de diâmetro, em que para CC o maior número de indivíduos foi na classe de diâmetro de 10-14,9 cm e para CA na classe de 5-9,9 cm (Figura 2). A distribuição dos diâmetros da comunidade apresentou tendência similar entre as duas áreas, enquanto $57,4 \%$ dos indivíduos possuíam diâmetro inferior a $15 \mathrm{~cm}$ na área de cerrado conservado, na área não conservada esse valor foi de $61,46 \%$ (Figura 3). Na área conservada ocorreu maior número de indivíduos nas classes de maiores diâmetros. 
Figura 1 - Curvas de rarefação de duas áreas de cerrado do campus da Universidade Estadual de Goiás, Ipameri - GO. Cerrado conservado CC (Linha contínua preta - $S_{\text {obs }}-$ Mao Tau); (Linha pontilhada preta - Bootstrap) e Cerrado antropizado CA (Linha contínua cinza $-S_{\text {obs }}$ - Mao Tau); (Linha pontilhada cinza - Bootstrap)

Figure 1 - Rarefaction curves of two savannah areas of the Goiás State University Campus, Ipameri - GO. Conserved Cerrado CC (Black Continuous Line - $\mathrm{S}_{\text {obs }}$ - Mao Tau); (Black Dotted Line - Bootstrap) and CA AnthropisatedCerrado (Gray Continuous Line - $\mathrm{S}_{\text {obs }}$ - Mao Tau); (Gray Dotted Line - Bootstrap)

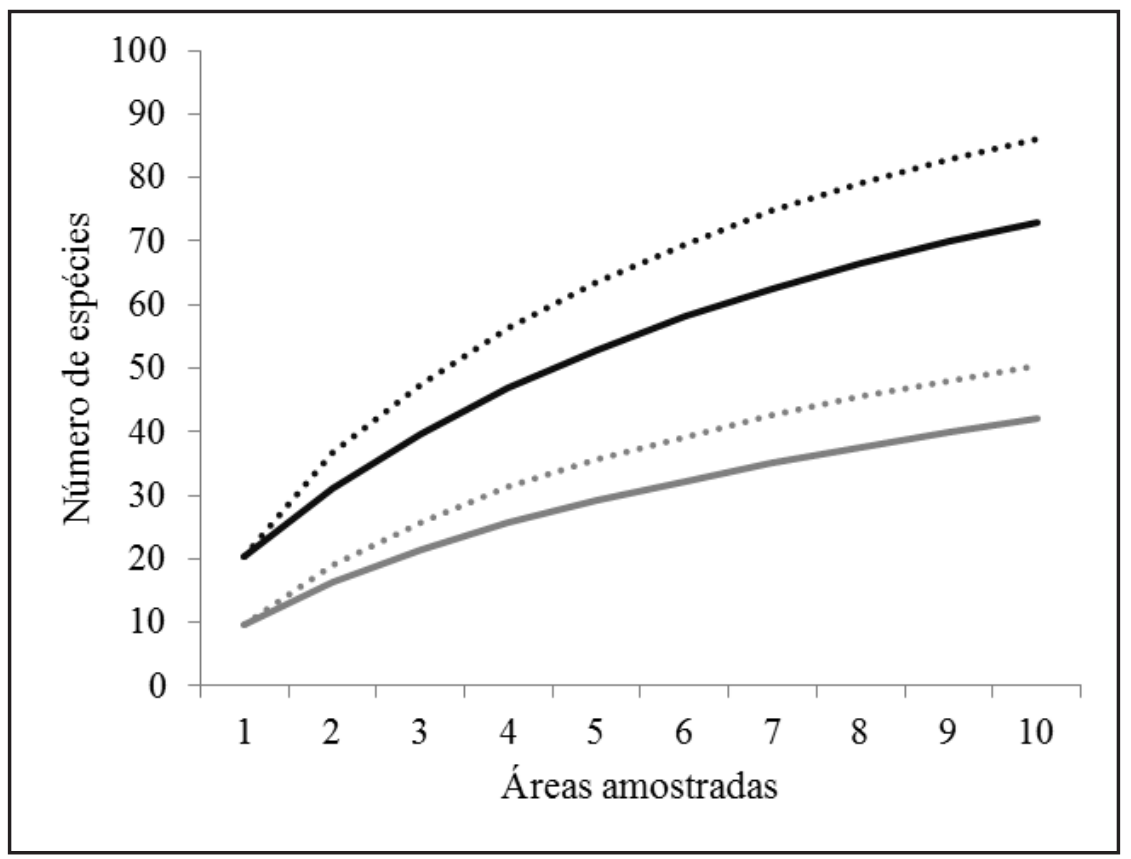

Fonte: Autores (2018)

Tabela 2 - Teste t de Student para variáveis bióticas entre área conservada e antropizada de cerrado stricto sensu no município de Ipameri-GO

Table 2 - Student's t-test for biotic variables between conserved and anthropizedcerradostrictosensu area in the city of Ipameri-GO

\begin{tabular}{lccccc}
\hline \multicolumn{1}{c}{ Parâmetros } & Área Conservada & Área Antropizada & G.L. & $\mathbf{t}$ & $\mathbf{p}$ \\
\hline $\mathbf{N}^{\circ}$ Espécies & 67 & 40 & 18 & 5,08 & $<0,001$ \\
$\mathbf{N}^{\circ}$ Indivíduos $\left(\right.$ ind $\left.^{*} \mathbf{h a}^{-}{ }^{\mathbf{1}}\right)$ & 676 & 192 & 18 & 6,20 & $<0,001$ \\
Área basal $\left(\mathbf{m}^{2 *} \mathbf{h a}^{-1}\right)$ & 17,33 & 4,16 & 18 & 7,27 & $<0,001$ \\
Índice de Shannon $\left(\mathbf{H}^{\prime}\right)$ & 3,00 & 2,96 & 18 & 3,81 & 0,001 \\
Equitabilidade $\left(\mathbf{J}^{\prime}\right)$ & 0,74 & 0,73 & 18 & 0,70 & 0,464 \\
\hline
\end{tabular}

Fonte: Autores (2018) 
Figura 2 - Distribuição das classes de diâmetro dos indivíduos de duas áreas comparadas de cerrado stricto sensu, sendo uma delas impactada, localizadas no campus da Universidade Estadual de Goiás, Ipameri - GO

Figure 2 - Distribution of the diameter classes of individuals from two compared areas of cerradostrictosensu, one of them being impacted, located at the Goiás State University Campus, Ipameri - GO

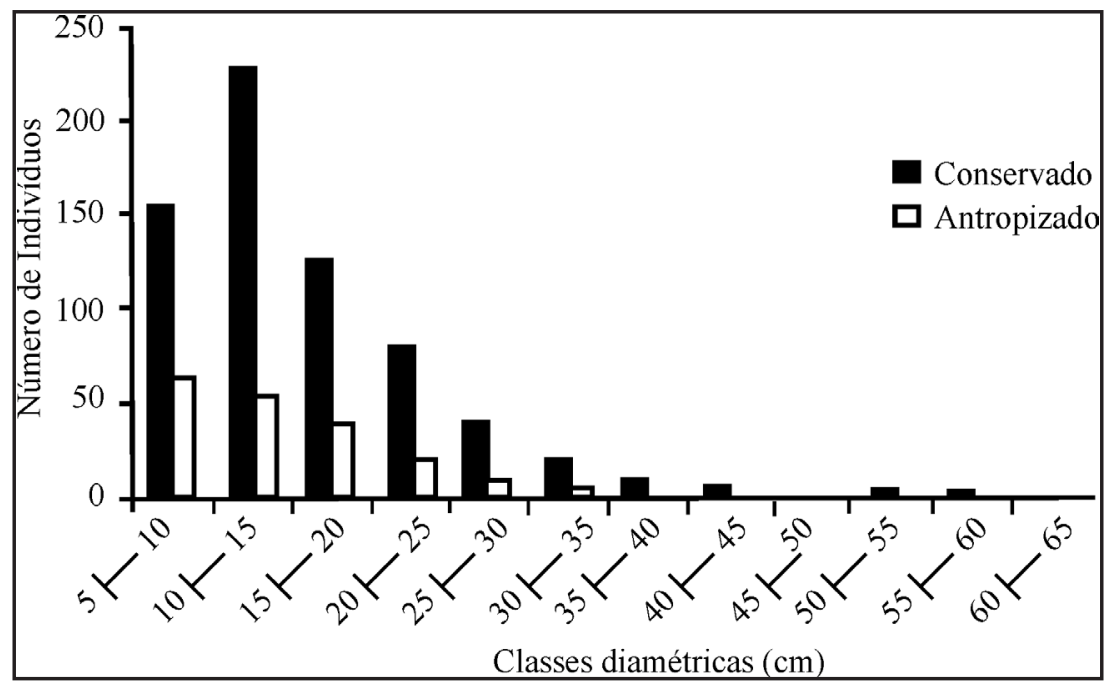

Fonte: Autores (2018)

Figura 3 - Distribuição das classes de altura dos indivíduos de duas áreas comparadas de cerrado stricto sensu, sendo uma delas impactada, localizadas no campus da Universidade Estadual de Goiás, Ipameri - GO

Figure 3 - Distribution of height classes of individuals from two comparative areas of cerradostrictosensu, one of them being impacted, located at the Goiás State University Campus, Ipameri - GO

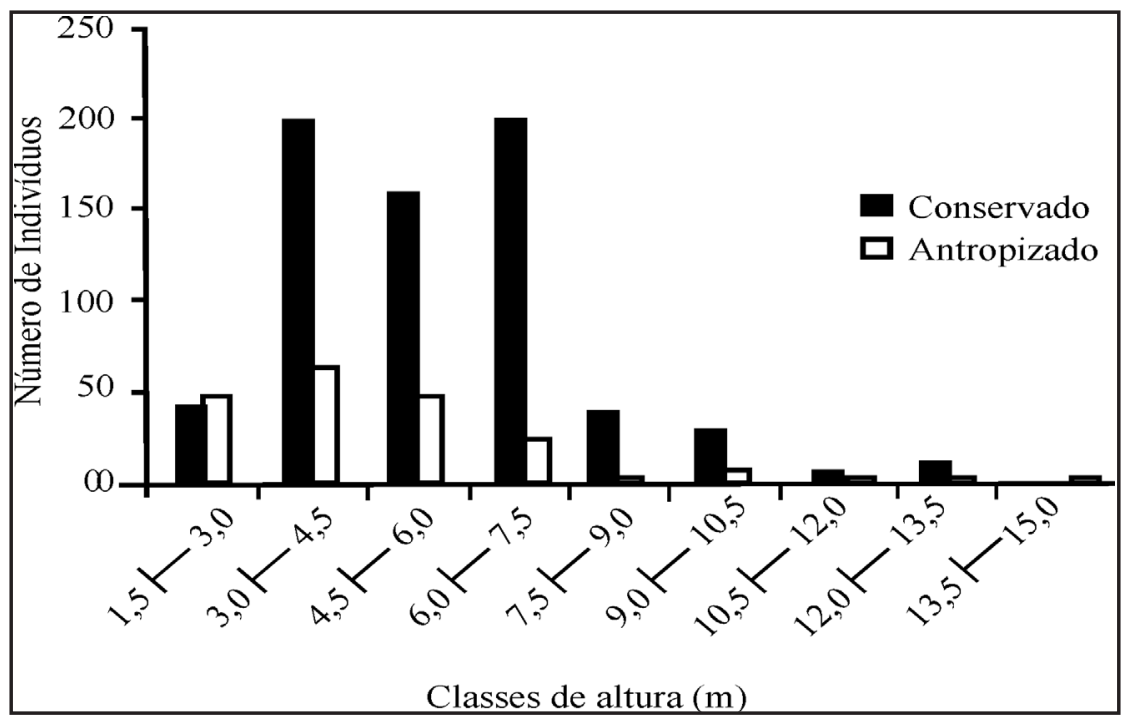

Fonte: Autores (2018) 
Os maiores valores de altura se concentraram entre $1,5 \mathrm{~m}$ a $7,5 \mathrm{~m}$, sendo $89,75 \%$ dos indivíduos de CC e 93,23\% dos indivíduos de CA (Figura 4). Apenas 12 indivíduos (1,38\% do total), pertencentes a nove espécies, apresentaram altura superior a $12 \mathrm{~m}$ : Tachigali aurea, Terminalia argentea, Tapirira guianensis, Emmotum nitens, Qualea grandiflora, Richeria grandis, Tachigali paniculata, Vochysia tucanorum, Terminalia argentea e Astronium graveolans.

Figura 4 - Decorana pelo método de ordenação - DCA para duas áreas de cerrado em 10 parcelas ( 1 hectare) de CC (esfera preta) e 10 parcelas ( 1 hectare) de CA (esfera branca),

localizadas no campus da Universidade Estadual de Goiás, Ipameri - GO. Círculo demarcado com linhas pretas representa o grupo da CC e círculo tracejado representa o grupo da CA

Figure 4 - Decorating by the ordination method - DCA for two cerrado areas in 10 plots (1 hectare) of CC (black sphere) and 10 plots (1 hectare) of CA (white sphere), located at the Goiás

State University Campus. Ipameri - GO. Circle marked with black lines represents the DC group and dashed circle represents the AC group

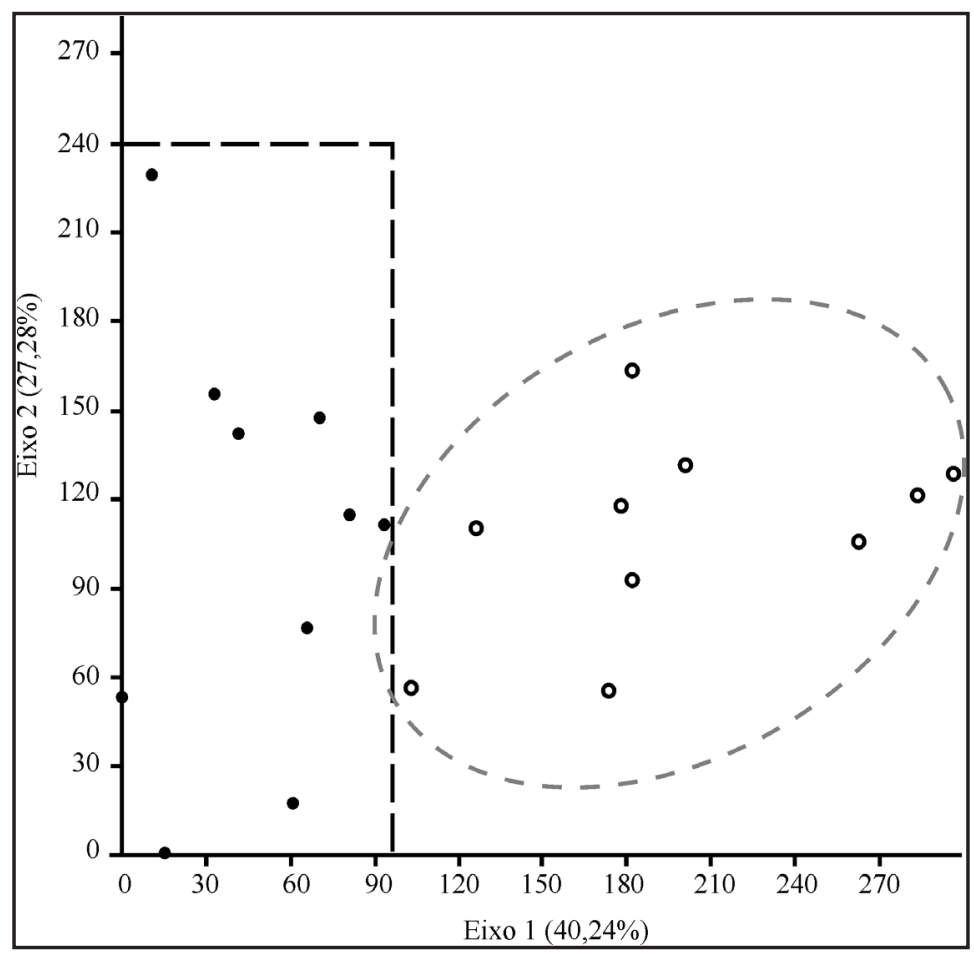

Fonte: Autores (2018)

O dendrograma de similaridade baseado no índice de Sørensen (Figura 5A) formou um grupo com sete parcelas da área antropizada, porém com baixa similaridade entre si (próximo a 20\%). Outro grupo, formado pelas dez parcelas do CC e uma do CA, apresentou maior similaridade (acima de 40\%), e duas parcelas do CA não formaram grupos. Um padrão semelhante ocorreu com o dendrograma baseado na similaridade de Bray-Curtis (Figura 5B), entretanto com formação de três grupos com maior similaridade entre si. Um formado por sete parcelas do CA (similaridade acima de 30\%), outro formado por 10 parcelas do CC e uma do CA (similaridade próximo a 40\%) e outro formado por duas parcelas do CA (similaridade de $40 \%$ ). 


\section{Figura 5 - Dendrograma de similaridade de Sørensen e Bray-Curtis realizados através da média de grupo (UPGMA) para duas áreas de cerrado com diferentes históricos de uso}

Figure 5 - Sørensen and Bray-Curtis similarity dendrogram performed through group mean (UPGMA) for two cerrado areas with different use histories

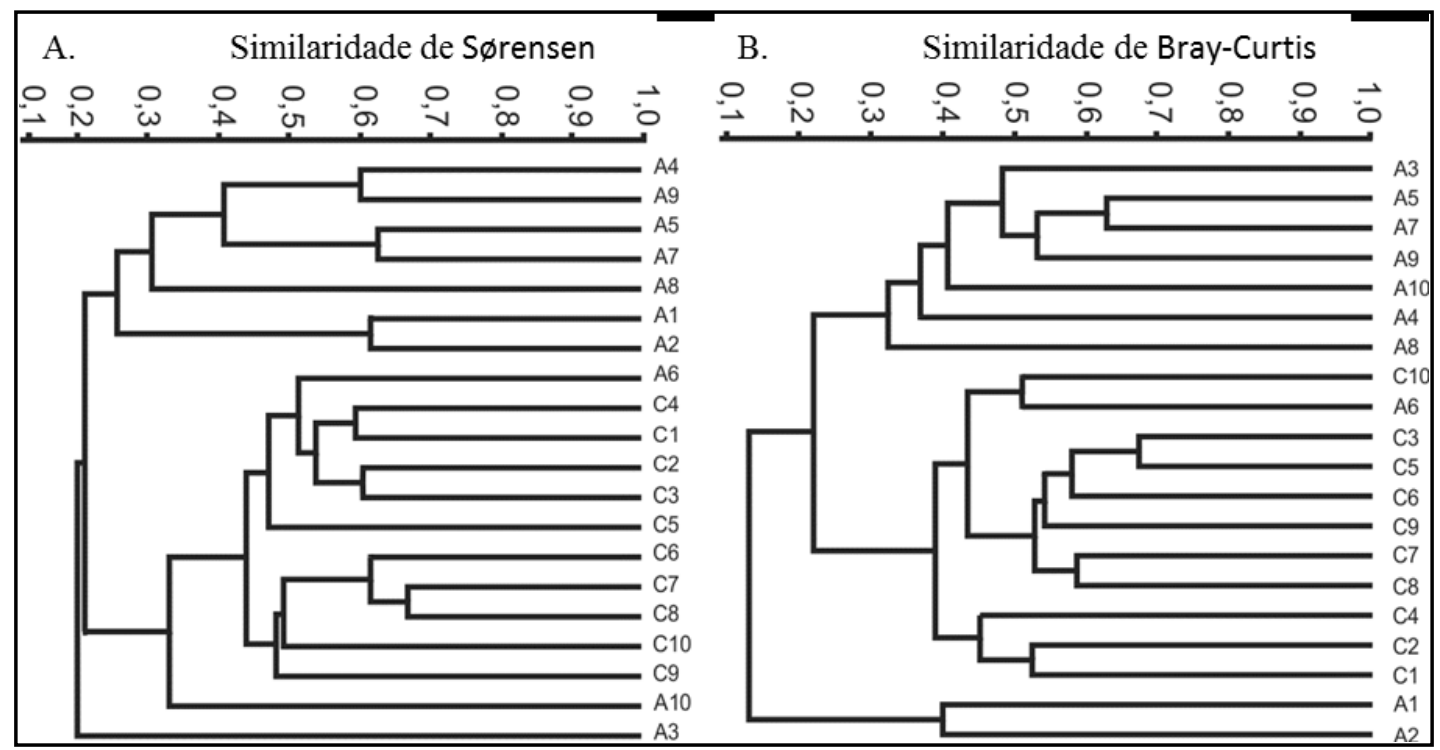

Fonte: Autores (2018)

A primeira divisão do método Twinspan, cujo autovalor foi considerado alto $(0,538)$, formou dois grandes grupos. O primeiro formado por parcelas do cerrado conservado e as parcelas 6 e 10 do cerrado alterado, cujas espécies indicadoras foram Caryocar brasiliense e Terminalia argentea; e o segundo formado pelas demais parcelas do cerrado antropizado (Figura 6). Do primeiro grupo, uma segunda divisão do Twinspan separou as parcelas do cerrado conservado das duas parcelas do cerrado alterado, mais uma do cerrado conservado. As espécies indicadoras desses grupos estão evidenciadas na Figura 6. A divisão é considerada representativa quando os autovalores estão próximos ou acima de 0,30 , e, para essas duas divisões, os valores foram superiores a 0,40 ; logo, a análise pode ser considerada eficiente, do ponto de vista que confirma a existência de três grupos florísticos: 8 parcelas do cerrado antropizado; 2 parcelas do cerrado antropizado e todas as parcelas do cerrado conservado. A separação dos dois grupos antropizados pode ter ocorrido em função do efeito de borda, o qual influenciaria a estrutura florística presente em algumas parcelas, através de ações ambientais como a variação de temperatura, vento, umidade, etc.

Tanto a abordagem clássica quanto a abordagem multivariada foram eficientes em demonstrar as diferenças de uma área claramente impactada (CA) e outra cujos impactos antrópicos são menores (CC). As análises foram eficientes em demonstrar que, na região mais conservada, sem histórico de uso, existe claramente uma diferenciação florística e estrutural em relação à área antropizada. A baixa riqueza (menor que 50) e diversidade (menor que 3,00) da área antropizada demonstra valores baixos em relação a outras áreas de Goiás (LOPES et al., 2011). Lopes et al. (2011), comparando 16 áreas de cerrado sentido restrito, mostram que o padrão de diversidade para o cerrado restrito do Brasil Central aponta variação no índice de Shannon de 3,02 a 3,69. Áreas com forte histórico de perturbação tendem a possuir baixa riqueza e diversidade (VALE; CRESPILHO; SCHIAVINI, 2009) e valores inferiores a 50 espécies e 3,0 podem ser considerados baixos comparados aos valores encontrados para cerrados sentido restrito. A área conservada ficou dentro dos padrões para os cerrados da região.

$\mathrm{Na}$ área antropizada, tanto os valores de densidade quanto a área basal apresentaram 
valores inferiores a diversos outros estudos realizados em cerrados stricto sensu, mostrandose muito abaixo da média que ocorre em cerrados com essas características, cuja área basal média varia entre 5,8 a 10,8 $\mathrm{m}^{2} / \mathrm{ha}^{-1}$ (FELFILI et al., 2001). Na área antropizada, tanto os valores de densidade quanto a área basal apresentaram valores inferiores a diversos outros estudos realizados em cerrados stricto sensu, mostrando-se muito abaixo da média para cerrados, cujos valores para área basal variam entre 6 a $12 \mathrm{~m}^{2} / \mathrm{ha}^{-1}$ (FELFILI et al., 2001; LOPES et al., 2011) e

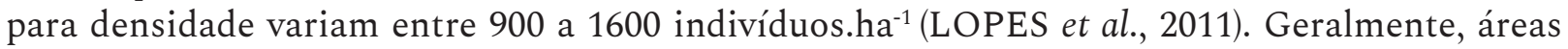
de cerrado próximas a centros urbanos (PAULA; IMAÑA-ENCINAS; SANTANA, 2007), com impactos recorrentes ou com histórico de uso intenso tendem a possuir menores densidade e áreas basais, devido ao alto grau de antropização. Todas as classes diamétricas do CA foram inferiores aos CC, apresentando-se deterioradas, demonstrando o quão forte foram os impactos passados.

Figura 6 - Classificação pelo método Twinspan das duas áreas comparadas de cerrado stricto sensu, sendo uma delas impactada, localizadas no campus da Universidade Estadual de Goiás, Ipameri - GO

Figure 6 - Classification by the Twinspan method of the two compared areas of cerradostrictosensu, one of them being impacted, located at the Goiás State University Campus, Ipameri - GO

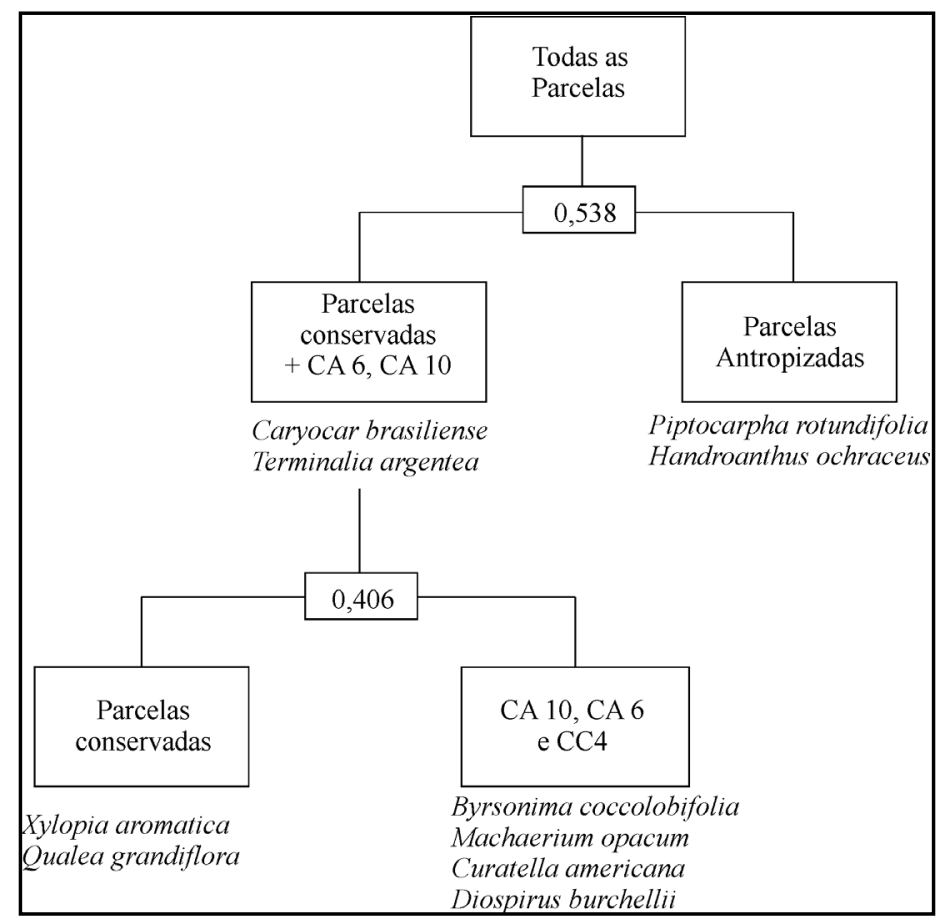

Fonte: Autores (2018)

No sistema de produção de bovinos a pasto, o sombreamento natural é um recurso que contribui para o suprimento de bem-estar dos animais (NAVARINI et al., 2009), fato que ocorreu na área de estudo até o início dos anos 2000. No entanto, não há indivíduos superiores a $35 \mathrm{~cm}$ de circunferência e poucos com altura superior a $10 \mathrm{~m}$, logo, a maioria das árvores devem ter sido derrubadas para a manutenção do pasto no passado. Dessa forma, mesmo mais de 15 anos depois, o cerrado não apresenta estrutura semelhante a outros cerrados conservados na região, assim, ações de manejo devem ser propostas para a recuperação da estrutura local.

A exceção da equitabilidade, todos os parâmetros utilizados para a comparação das duas 
áreas foram eficientes em demonstrar as diferenças entre as áreas. O número de espécies, a densidade arbórea, a área basal e o índice de diversidade de Shannon são úteis e devem ser utilizados para essas comparações e aferições de grau de conservação de áreas de cerrado. Comumente estudos fitossociológicos utilizam esses parâmetros para aferir impactos em vegetação nativa (LOPES et al., 2011). No presente estudo, a equitabilidade não foi relevante para aferir as diferenças entre as áreas e não parece ser útil para aferir o grau de conservação. Geralmente, a equitabilidade, independentemente do grau de antropização da área, tende a estar entre 0,75 e 0,85 (LOPES et al., 2011), pouco inferindo sobre essa questão.

Mesmo tendo ocorrido mais espécies na CC, em ambas as áreas, a curva do coletor não estabilizou com uma amostragem de 1 hectare. Dessa forma, apesar de útil para interpretações ecológicas, a simples estabilização ou não de espécies (para amostragens de 1 ha $^{-1}$ ou inferiores) não foi eficiente.

As classes de tamanho foram importantes para demonstrar graficamente as diferenças entre as duas áreas. Para praticamente todas as classes (tanto de tamanho quanto de altura) ficaram evidentes as diferenças. Por serem muito recorrentes na bibliografia, as classes de tamanho são muitas vezes negligenciadas em estudos fitossociológicos, sobretudo pela dificuldade de comparação entre diferentes áreas, pois muitos estudos utilizam classes (com diferentes intervalos de tamanhos diferentes ou buscam explicar como as figuras se comportaram) especialmente em relação à ocorrência de J-reverso ou não (ASSUNÇÃO; FELFILI, 2004; PAULA et al., 2009; MOURA et al., 2010). Ainda assim, para se compararem áreas com diferentes históricos de antropização, os gráficos foram eficientes em demonstrar as singularidades entre ambas. Acredita-se ser necessária uma padronização quanto aos intervalos das classes de tamanho para facilitar tais comparações.

A análise multivariada Decorana e os dendrogramas foram úteis em apresentar uma noção espacial de cada parcela e o quanto as áreas são distintas, mesmo estando adjacentes. A Decorana formou dois grandes grupos distintos nos quais mesmo quando a parcela da CA estava próxima na paisagem em relação às parcelas da $\mathrm{CC}$, apresentou distinção suficiente para alocá-la no grupo das parcelas da CA, mesmo quando compartilhavam espécies em comum, principalmente por diferenças de densidade. Logo, quando se compilam dados estruturais, o uso dessa metodologia potencializa a percepção do grau de conservação de cada parcela.

Já a análise multivariada Twinspan separou 8 das 10 parcelas da CA em um grupo único (chamado de parcelas antropizadas), com espécies indicadoras, listadas na Figura 6. As outras duas parcelas alocadas na área antropizada foram agrupadas junto com a CC, indicando semelhanças entre essas áreas. As parcelas 6 e 10 são as parcelas mais próximas da CC e compartilham espécies em comum, esse fato pode ter sido primordial para a formação desse grupo. Uma segunda subdivisão alocou essas duas parcelas da CA (6 e 10) juntas com a CC4, demonstrando que devem ser as parcelas com melhor recuperação pós-uso. Dessa forma, o Twinspan foi uma análise que possibilitou uma melhor depuração dos dados, indicando inclusive parcelas com provável melhor recuperação pós-uso. As análises multivariadas permitem, então, evidenciar detalhes que, com apenas a aferição das variáveis estruturais, não seriam possíveis.

De um modo geral, as três análises multivariadas propostas convergiram para os mesmos resultados, detalhando melhor as diferenças entre as áreas estudadas e sendo recomendadas para agregar informações em estudos fitossociológicos a serem incorporadas em relatórios técnicos (IBAMA, 2009; EMBRAPA CERRADOS, 2014).

A complexidade do cerrado sentido restrito levou à subdivisão em fisionomias distintas principalmente em: o cerrado típico e o cerrado ralo, que refletem variações na forma dos agrupamentos e espaçamento entre os indivíduos lenhosos. O cerrado ralo é caracterizado como um subgrupo de formação natural ou antropizado que apresenta uma fisionomia arbórea rala e outra graminoide contínua, sujeita ao fogo anual (IBGE, 2012). A área amostrada sofreu com constantes impactos antrópicos, sobretudo histórico de uso para pastagem, assim, a área com o tempo adquiriu as características de cerrado ralo, em decorrência dessa antropização. Queimadas, 
mesmo que frequentes, podem não alterar a estrutura e composição de cerrados (LOPES; VALE; SCHIAVINI, 2009), então, outras atividades antrópicas existentes na área parecem ter contribuído para a deterioração da vegetação. Fatores como: evidências de uso constante do fragmento como pastagem, no passado; uso de todo entorno pela agricultura convencional (soja, milho, girassol); existência de uma voçoroca no interior do fragmento e presença de gramíneas invasoras.

\section{Conclusões}

Tanto a abordagem clássica quanto a multivariada foram eficientes em demonstrar as diferenças entre as áreas. A equitabilidade e a estabilização da curva do coletor foram ineficientes em demonstrar tais diferenças e não devem ser utilizadas com tal finalidade. As análises multivariadas foram eficientes no detalhamento das diferenciações estruturais de cada área e devem ser incentivadas nos relatórios técnicos e estudos com finalidade comparativa.

\section{Referências}

ALVARES, C. A. et al. Koppen's climate classification map for Brazil. Meteorologische Zeitschrift, Stuttgart, v. 22, n. 6, p. 711-728, 2014.

ASSUNÇÃO, S. L.; FELFILI, J. M. Fitossociologia de um fragmento de cerrado sensu stricto na APA do Paranoá, DF, Brasil. Acta Botanica Brasilica, Belo Horizonte, v. 18, n. 4, p. 903-909, 2004.

BRASIL. Ministério do Meio Ambiente. $5^{\circ}$ Relatório nacional para a Convenção Sobre Diversidade Biológica. Brasil, 2016. 240 p.

COLWELL, R. K. EstimateS: Statistical esmation of spencies richness and shared species from samples. Version 9.1.0. [S. l.: s. n.], 2013.

EISENLOHR, P. V. et al. Fitossociologia no Brasil: métodos e estudos de casos. Viçosa, MG: Editora UFV, 2011.556 p.

EMBRAPA. Sistema Brasileiro de Classificação de Solos. Rio de Janeiro: EMBRAPA Solos, 2006. 306 p.

EMBRAPA CERRADOS. Relatório de atividades da Embrapa Cerrados: 2011 a 2013. Brasília, 2014. 96 p.

FELFILI,J.M.; CARVALHO, F.A.; HAIDAR, R. F. Manual para o monitoramentode parcelas permanentes nos biomas Cerrado e Pantanal. Brasília: Universidade de Brasília, Departamento de Engenharia Florestal, 2005. $55 \mathrm{p}$.

FELFILI, J. M. et al. Changes in the floristic.composition of cerrado sensu strictu in Brazil over nine-year period. Journal of Tropical Ecology, Cambridge, v. 16, p. 579-590, 2000.

FELFILI, J. M. et al. Fitossociologia da vegetação arbórea. In: FELFILI, J. M.; SILVA-JÚNIOR, M. C. (ed.). Biogeografia do bioma cerrado: estudo fitofisionômico na Chapada do Espigão Mestre do São Francisco. Brasilia, DF: UnB, 2001. p. 35-56.

GOTELLI, N. J.; CHAO, A. Measuring and estimating species richness, species diversity, and biotic similarity from sampling data. Encyclopedia of Biodiversity, San Diego, v. 5, p. 195-211, 2013.

GOTELLI, N. J.; ELLISON, A. M. Princípios de estatística em ecologia. 1. ed. Porto Alegre: Artmed, 2011. $532 \mathrm{p}$.

GUSSON, E. A. et al. A importância de uma análise comparativa detalhada: comparando a estrutura arbórea de dois fragmentos de Floresta Estacional Semidecidual no Triângulo Mineiro. Brazilian Geographical Journal: Geosciences and Humanities Research Medium, Ituiutaba, v. 3, n. 2, p. 471-485, 2012.

HAMMER, O. et al. Paleontological Statistics software package for education and data analysis. Palaeontologia Electronica, [s. l.], v. 4, n. 1, p. 9, 2001. 
HILL, M. O. TWINSPAN: A FORTRAN Program for Arranging Multivariate Data in an Ordered Two Way Table by Classification of Individual and Attributes Ecology and Systematics. Ithaca: Cornell University, $1979.90 \mathrm{p}$.

IBAMA. Relatório Técnico de Monitoramento do desmatamento no Bioma Cerrado, 2002 a 2008: Dados Revisados. Brasília, 2009. 71 p.

IBGE. Manual Técnico da Vegetação Brasileira. Rio de Janeiro, 2012. 271 p.

IBGE. Mapa de biomas do Brasil. Escala 1:5.000.000. Rio de Janeiro: IBGE, 2004. Disponível em: http:// mapas.ibge.gov.br/biomas2/viewer.htm. Acesso em: 20 ago. 2018.

KOTTEK, M. et al. World Map of the Köppen-Geiger climate classification updated. Meteorologische Zeitschrift, Stuttgart, v. 15, n. 3, p. 259-263, 2006.

LEHMANN, C. E. R. et al. Savanna Vegetation-Fire-Climate Relationships Differ Among Continents. Science, New York, v. 343, p. 548-552, 2014.

LOPES, S.F. et al. Análise comparativa da estrutura e composição florística de Cerrado no Brasil central. Interciencia, Caracas, v. 36, n. 1, p. 8-15, 2011.

LOPES, S. F.; VALE, V.S.;SCHIAVINI, I. Efeito de queimadas sobre a estrutura e composição da comunidade vegetal lenhosa do cerado sentido restrito em Caldas Novas, GO. Revista Árvore, Voçosa, MG, v. 33, n. 4, p. 695-704, 2009.

MIRANDA, H. S. et al. Queimadas de Cerrado: caracterização e impactos. In: AGUIAR, L. M. S.; CAMARGO, A. J. A. (ed.). Cerrado: ecologia e caracterização. Planaltina: EMBRAPA Cerrados, 2004. p. 69-123.

MOURA, I. O. et al. Diversidade e estrutura comunitária de cerrado sensu stricto em afloramentos rochosos no parque estadual do Pirineus, Goiás. Revista Brasileira de Botânica, São Paulo, v. 33, n. 3, p. 455-467, 2010.

NAVARINI, F. C. et al. Conforto térmico de bovinos da raça nelore a pasto sob diferentes condições de sombreamento e a pleno sol. Revista Engenharia Agrícola, Jaboticabal, v. 29, n. 4, p. 508-517, 2009.

PAULA, J. E. et al. Levantamento florístico e sua distribuição diamétrica da vegetação de um cerrado sensu stricto e de um fragmento de floresta de galeria no ribeirão Dois Irmãos na APA de Cafuringa, DF, Brasil. Biotemas, Florianópolis, v. 22, n. 3, p. 35-46, 2009.

PAULA, J. E.; IMAÑA-ENCINAS, J. I.; SANTANA, O. A. Levantamento florístico e dendrométrico de um hectare de Cerrado sensu stricto em Planaltina, Distrito Federal. Revista Brasileira de Ciências Agrárias, Recife, v. 2, n. 4, p. 292-296, 2007.

PINHEIRO, E. S.; DURIGAN, G. Dinâmica espaço-temporal (1962-2006) das fitofisionomias em unidade de conservação do Cerrado no sudeste do Brasil. Revista Brasileira de Botânica, São Paulo, v. 32, n. 3, p. 441-454, 2009.

SANO, E. E. etal. Spatial and temporal probabilities of obtaining cloud-free Landsat images over the Brazilian tropical savanna. International Journal of Remote Sensing, [s. l.], v. 28, p. 2739-2752, 2007.

SHEPHERD, G. J. Fitopac 2.1.2.85. Manual do Usuário. Campinas: Universidade Estadual de Campinas, Departamento de Botânica, 2010.

SLOAN, S. et al. Remaining natural vegetation in the global biodiversity hotspots. Biological Conservation, [s. l.], v. 177, p. 12-24, 2014.

VALE, V. S.; CRESPILHO, R. F.; SCHIAVINI, I. Annalysis of an natural regeneration in a vegetal community of cerrado in Parque Victório Siquierolli, Uberlândia-MG. Bioscience Journal, Uberlândia, v. 25, n. 1, p. 131$145,2009$.

WANG, J. SPECIES: An R Package for Species Richness Estimation. Journal of Statistical Software, [s. l.], v. 40, n. 9, apr. 2011. 